\title{
Evaluation and Improvement of Roundabouts in Changchun
}

\author{
Mo Zhou' ${ }^{1}$, Lili Yang ${ }^{2}$, Hoong Chor Chin ${ }^{1}$ \\ ${ }^{1}$ Department of Civil \& Environmental Engineering, National University of Singapore, Singapore City, Singapore \\ ${ }^{2}$ Institute of Transportation, Jilin University, Changchun, China \\ Email: zhou_mo@u.nus.edu,yangll105@126.com,chin.hc@nus.edu.sg
}

How to cite this paper: Zhou, M., Yang, L.L. and Chin, H.C. (2016) Evaluation and Improvement of Roundabouts in Changchun. World Journal of Engineering and Technology, 4, 40-50. http://dx.doi.org/10.4236/wjet.2016.43C006

Received: July 18, 2016

Accepted: September 19, 2016

Published: September 22, 2016

\begin{abstract}
In Changchun, China, roundabouts are fairly common. They are often designed to connect the main roads because of their ability to reduce conflict points, making them safer than other intersections. They can also beautify the city when the central islands are landscaped. However, with increasing traffic, they may not function well and may even paralyze the road network. This means that it is important to evaluate the performance of roundabouts promptly, and to make necessary improvements if required. Using several roundabouts in Changchun as case studies, this article uses $\mathrm{V} / \mathrm{C}$ ratio and delay to evaluate roundabout performance. Based on the result of evaluation, the micro-simulation model of the poorly-performing roundabout is built and enhancement is proposed.
\end{abstract}

\section{Keywords}

Roundabouts, V/C Ratio and Delay Evaluation, Traffic Simulation, AIMSUN

\section{Introduction}

Numerous roundabouts are in use in Changchun, China, some of which designed to connect arterials. The roundabouts within the inner circle of Changchun is marked in Figure 1. In recent times, several roundabouts are at critical point of breakdown, experiencing prolonged delays and long queues. Without timely interventions to improve their performance, not only will the congestion problem deteriorates, also the failing roundabout may even paralyze the whole road network. Therefore, it is highly necessary to assess the current status of the roundabout performance and to propose suitable modifications to avoid breakdown.

This article evaluates four typical roundabouts in Changchun, with the aim to understand roundabout performance. Using AIMSUN, the micro-simulation model of that 


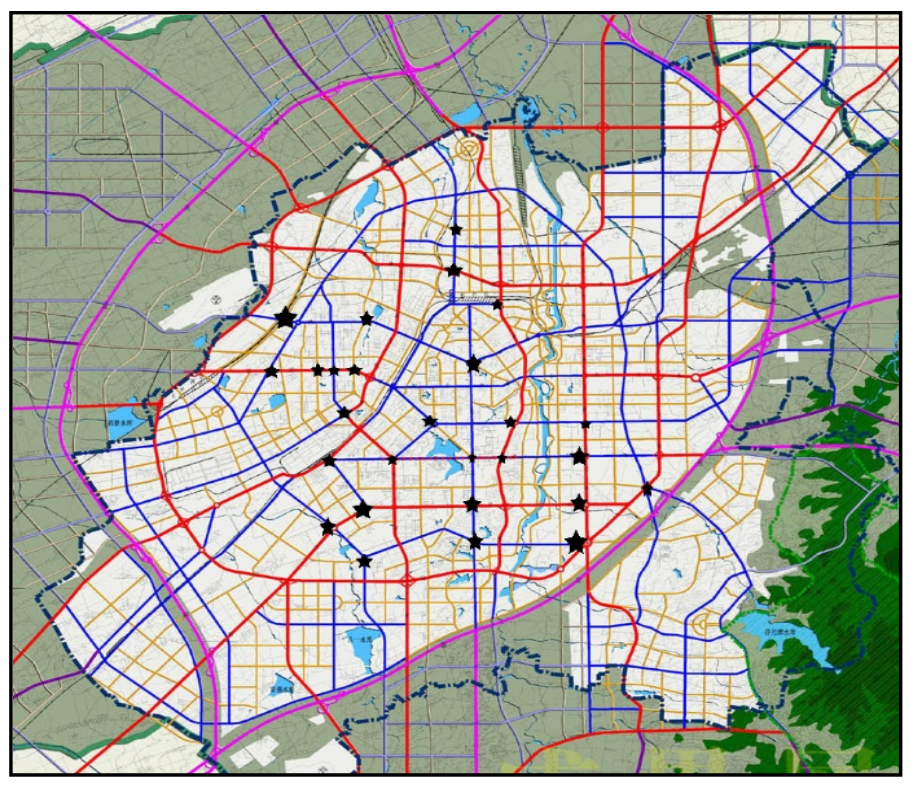

Figure 1. Distribution of roundabouts in Changchun.

roundabout is built in order to analyze the detailed causes of poor performance and to explore alternatives to improve performance. A general process of evaluating a roundabout and assessing improvements is then presented. The framework of this paper is shown in Figure 2.

Since there are some differences among the different types of roundabouts chosen, an evaluation index based on V/C ratios and delays are used respectively for unsignalized roundabouts and signalized roundabouts. The corresponding level of service is then used to reflect the performance of each roundabout. Using data collected at the sites, the microsimulation model is then checked and calibrated. Proposed changes to the roundabout are applied to the simulated model to test if performance can be improved.

\section{Features of the Roundabouts in Study}

\subsection{Classification of Roundabouts}

Based on the existence of traffic light and the number of connected lanes, the common roundabouts in Changchun can be classified into four types:

1) Unsignalized four-leg roundabouts (e.g. Weixing Square and Jingyang Square)

2) Signalized four-leg roundabouts (e.g. Xi'an Square)

3) Unsignalized five-leg roundabouts (e.g. Zhengyang Square and Zhanqian Square)

4) Signalized five-leg roundabouts (e.g. Nanhu Square and Xinmin Square)

An example of each type of roundabouts is used as case studies in this paper

\subsection{Basic Data Collection}

Table 1 shows the details related to the data collection plan. The evening peak periods are chosen as higher flows are present. 


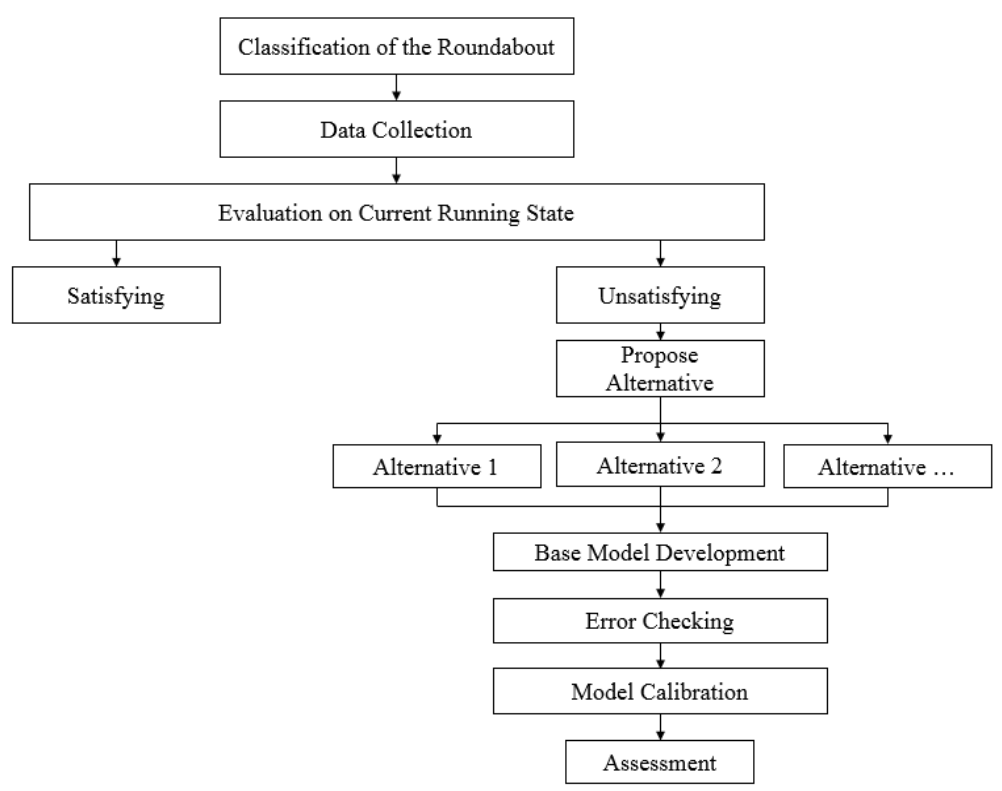

Figure 2. Framework overview.

Table 1. Data collection plan.

\begin{tabular}{ccc}
\hline Location & Time & Content \\
\hline Weixing Square & May $5^{\text {th }}$ & Road Inventory and Peak Hour Flow in \\
& $16: 30-18: 30$ & Each Weaving Sections \\
Weixing Square & May $10^{\text {th }}$ & Peak Hour Flow in Each Entrance Sections \\
& $16: 30-18: 30$ & and Turning Proportion \\
Zhengyang Square & May $17^{\text {th }}$ & Road Inventory and Peak Hour Flow in \\
& $16: 30-18: 30$ & Each Weaving Sections \\
Xinmin Square & May $18^{\text {th }}$ & Data needed for Individual Sample of \\
& $16: 30-18: 30$ & Stop Delay survey method \\
Xi'an Square & May 19 & Data needed for Individual Sample of \\
& $16: 30-18: 30$ & Stop Delay survey method \\
\hline
\end{tabular}

\section{Evaluation of the Roundabouts in Changchun}

\subsection{Unsignalized Four-Leg Roundabout-Weixing Square}

The roundabout at Weixing Square is one of the more important ones in Changchun.

Figure 3 shows the configuration of the roundabout.

The evaluation index of unsignalized multi-lane roundabout is the V/C ratio of weaving section [1]. This is computed using the geometric data from digital map and peak hour flow using the Index Calculator, as illustrated in Figure 4.

The corresponding levels of service based on the computed V/C ratios [2] are shown in Table 2.

As shown in Table 2, weaving sections 2 and 4 are at level of service F, indicating long queues and delays, implying that actions must be taken to improve the performance. 


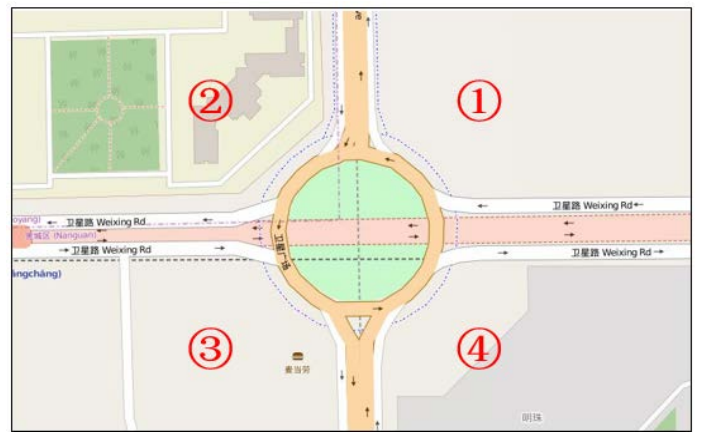

Figure 3. Weaving sections in Weixing Square.

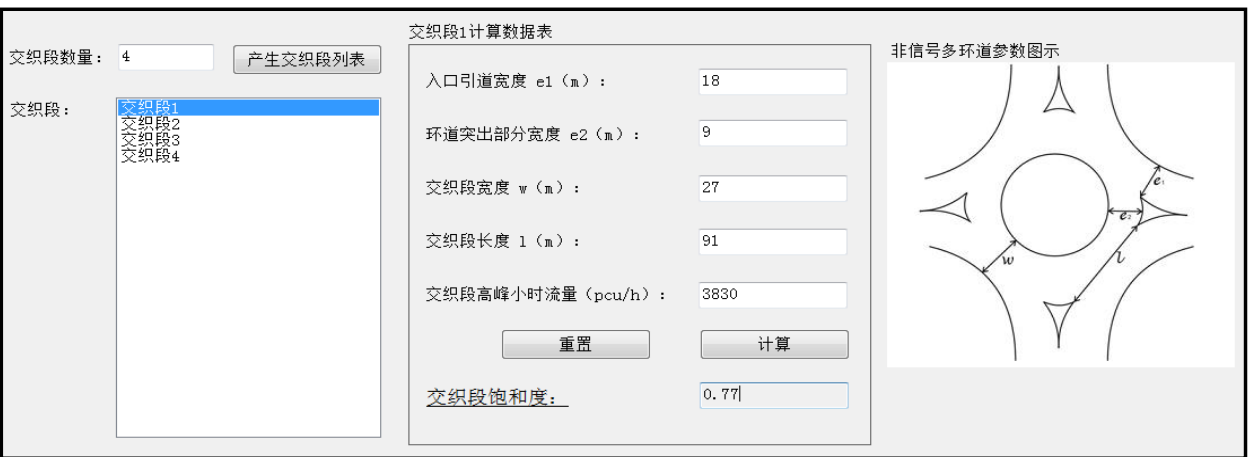

Figure 4. User interface of the index calculator.

Table 2. V/C ratios and levels of service of each weaving sections in Weixing Square.

\begin{tabular}{ccccc}
\hline No. & 1 & 2 & 3 & 4 \\
\hline V/C Ratio & 0.72 & 0.95 & 0.77 & 0.97 \\
Level of Service & C & F & C & F \\
\hline
\end{tabular}

\subsection{Unsignalized Five-Leg Roundabout-Zhengyang Square}

Zhengyang Square is an unsignalized roundabout as shownin Figure 5.

Using the Index Calculator, the $\mathrm{V} / \mathrm{C}$ ratios and service levels are computed and shown in Table 3.

The roundabout is functioning acceptably though weaving sections 2 and 5 are near failure conditions.

\subsection{Signalized Four-Leg Roundabout}

Xi'an Square is one of the most important intersections in Changchun. As this is a signalized roundabout, the average delay is used to assess its performance [1]. In this case, individual stop delay is measured. The level of service is determined based on the Highway Capacity Manual (HCM) [3].

The average delay and level of service at Xi'an Square are shown in Table 4. The roundabout has not reached capacity, although the traffic flow are rather high in Xi'an Square. 


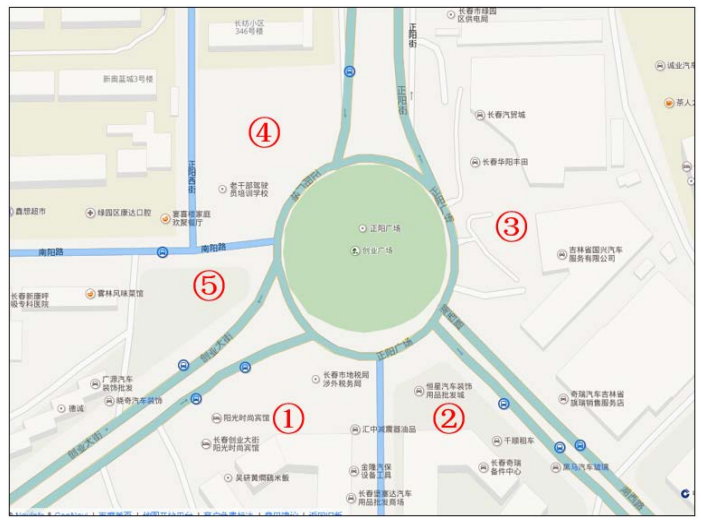

Figure 5. Weaving sections in Zhengyang Square.

Table 3. The V/C ratio and level of service of each weaving sections in Zhengyang Square.

\begin{tabular}{cccccc}
\hline No. & 1 & 2 & 3 & 4 & 5 \\
\hline V/C Ratio & 0.66 & 0.88 & 0.74 & 0.61 & 0.89 \\
Level of Service & B & E & C & B & E \\
\hline
\end{tabular}

Table 4. The average delay and level of service of each entrance sections in Xi'an Square.

\begin{tabular}{ccccc}
\hline Entrance & North & South & West & East \\
\hline Average Delay (s) & 26.3 & 19.0 & 39.8 & 38.4 \\
Level of Service & D & C & D & D \\
\hline
\end{tabular}

\subsection{Signalized Five-Leg Roundabout-Xinmin Square}

Xinmin Square is an example of a more complex signalized roundabouts in Changchun. The configuration of the roundabout is shown in Figure 6.

The average delay and service level of each leg is listed in Table 5.

The results show that during the afternoon peak, the traffic is high but the roundabout is operating just below capacity.

\section{Micro-Simulation of the Roundabout}

\subsection{Basic Model Development}

There has been past work done on simulating roundabouts [4] and Kotusevski, etc. [5] have compared several software in modeling roundabouts. Septarina [6] has made use of AIMSUN in modeling roundabouts in Sweden. In this paper, AIMSUN is used in developing the microsimulation model.

For the purpose of this paper, only the roundabout in Weixing Square is modeled to illustrate how changes to the roundabout can improve performance. Basic roundabout model has been established as is shown in Figure 7.

The traffic settings in the model are determined based on the traffic data collected. In order to define OD matrix and allocate the generation and attraction, centroid configuration is also necessary. Figure $\mathbf{8}$ demonstrates the four centroids of this roundabout. 
Table 5. The average delay and level of service of each entrance sections in Xinmin Square.

\begin{tabular}{cccccc}
\hline No. & 1 & 2 & 3 & 4 & 5 \\
\hline Average Delay (s) & 34.2 & 26.7 & 23.7 & 37.8 & 36.4 \\
Level of Service & $\mathrm{D}$ & $\mathrm{D}$ & $\mathrm{C}$ & $\mathrm{D}$ & $\mathrm{D}$ \\
\hline
\end{tabular}

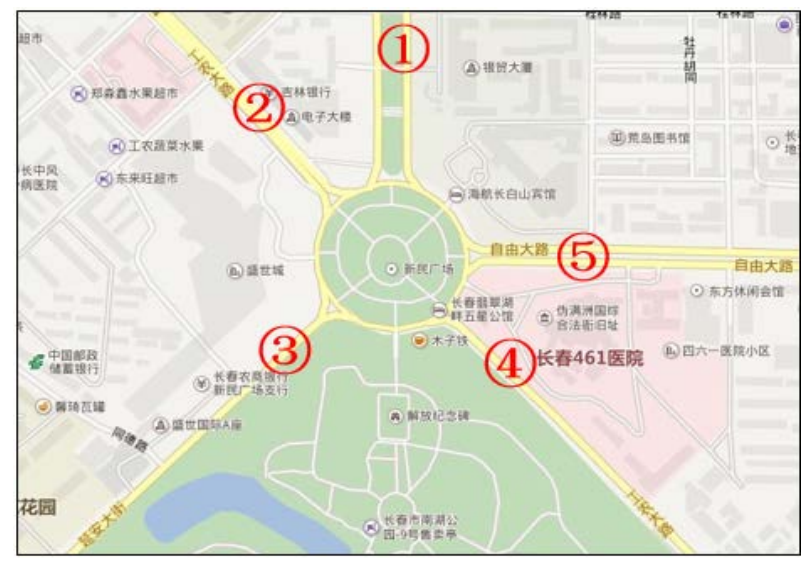

Figure 6. Five legs in Xinmin Square.

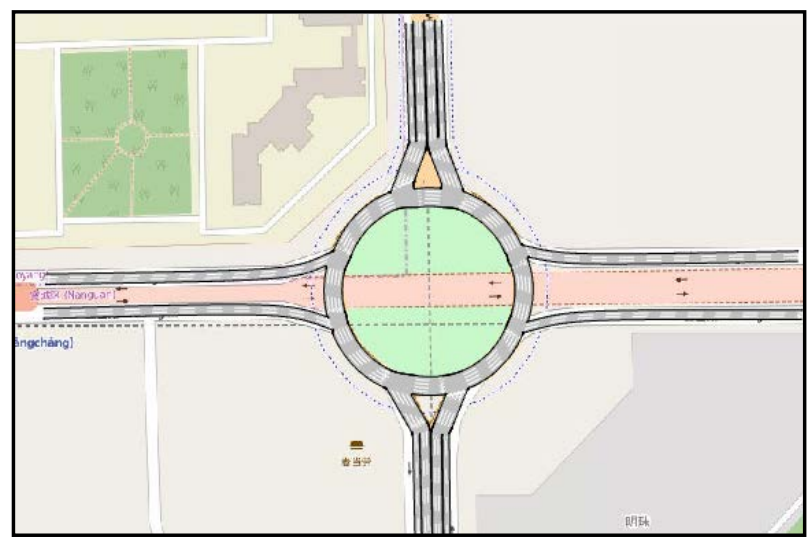

Figure 7. Base model.

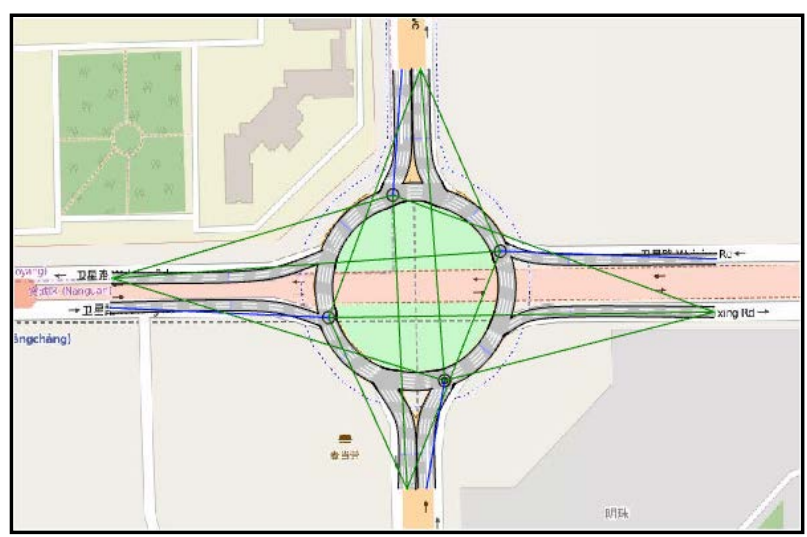

Figure 8. Centroid configuration. 
Blue lines represent generation, while green lines represent attraction. In this picture, every single line corresponds with a specific percentage.

The OD matrices for car and bus traffic are shown in Figure 9 and Figure 10 respectively.

A screenshot taken during the simulation process is shown in Figure 11.

The last step was to carry out error checking, which includes three stages: software error checking, input data error checking and animation error checking.

After checking the software and input data, animation is to be reviewed. Compared with the actual condition, the queue length in the simulation is slightly longer, which probably results from the default "offside priority rule". In addition, the traffic conditions in weaving section is slightly smoother than that in real-life scenario. This may be because the roundabout is affected by temporary construction within the central island resulting in a reduction in effective capacity in some weaving sections less than 5 . Nonetheless, in general, the animation is very close to reality.

\subsection{Model Parameters}

AIMSUN utilizes the Gipps model for updating the vehicle movements. This is shown in Equation (1) below.

\begin{tabular}{|l|l|l|l|l|l|}
\hline \multicolumn{2}{|c|}{$529: \mathrm{W}$} & \multicolumn{1}{|c|}{$534: \mathrm{N}$} & \multicolumn{1}{|c|}{$538: \mathrm{S}$} & \multicolumn{1}{c|}{ 542: $\mathrm{E}$} & \multicolumn{1}{c|}{ 计 } \\
\hline 529: & & 176 & 624 & 1156 & 1956 \\
\hline 534: N & 588 & & 236 & 880 & 1704 \\
\hline 538: S & 944 & 312 & & 716 & 1972 \\
\hline 542: E & 884 & 444 & 512 & & 1840 \\
\hline 合计 & 2416 & 932 & 1372 & 2752 & 7472 \\
\hline
\end{tabular}

Figure 9. OD Matrix of Car (vph).

\begin{tabular}{|c|c|c|c|c|c|}
\hline & 529:W & $534: \mathrm{N}$ & $538: 5$ & 542: E & 合计 \\
\hline 529: W & & 36 & 12 & 36 & 84 \\
\hline $534: \mathrm{N}$ & 20 & & 12 & 28 & 60 \\
\hline 538: S & 4 & 40 & & 24 & 68 \\
\hline 542: E & 4 & 24 & 40 & & 68 \\
\hline 合计 & 28 & 100 & 64 & 88 & 280 \\
\hline
\end{tabular}

Figure 10. OD Matrix of Bus (vph).

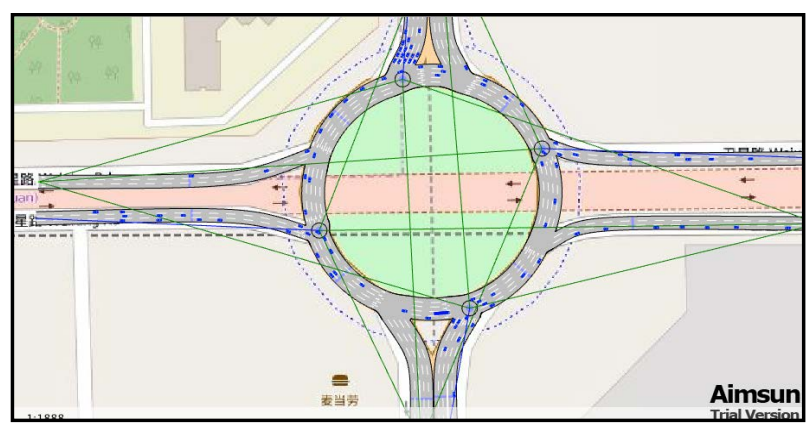

Figure 11. Screenshot of the simulation effect. 


$$
v_{n}(t+T)=\left\{\begin{array}{c}
v_{n}(t)+2.5 a_{n} T\left(1-\frac{v_{n}(t)}{V_{n}}\right) \sqrt{0.025+\frac{v_{n}(t)}{V_{n}}} \\
\left.-b_{n}\left(\frac{T}{2}+\theta\right)+\sqrt{b_{n}^{2}\left(\frac{T}{2}+\theta\right)^{2}+b_{n}\left\{2\left[x_{n-1}(t)-x_{n}(t)-S_{n-1}\right]-T v_{n}(t)+\frac{v_{n-1}^{2}(t)}{b_{n-1}}\right.}\right\}
\end{array}\right.
$$

where:

$$
\begin{aligned}
& a_{n}=\text { max acceleration of vehicle } n ; \\
& b_{n}=\text { max deceleration of vehicle } n ; \\
& b_{n-1}=\text { max deceleration of vehicle } n-1 ; \\
& T=\text { reaction time; } \\
& \theta=\text { reaction time to ensure safety; } \\
& V_{n}=\text { max expected speed of vehicle } n \text { in time } t \\
& V_{n}(t)=\text { speed of vehicle } n \text { in time } t \\
& X_{n}(t)=\text { driven distance of vehicle } \mathrm{n} \text { in time } t \\
& S_{n-1}=\text { effective length of vehicle } n-1
\end{aligned}
$$

Some of the parameters such as reaction time, speed limit, maximum acceleration, and maximum deceleration will need to be tested for sensitivity for the computation of performance criteria, e.g. queue length. From the earlier experimental runs, reaction time does not have a significant influence on average queue length. Moreover, given the "give way" protocol, the maximum give-way time should be taken into consideration.

The Root Mean Square Error method is used to obtain as the calibration criterion between the model measurements and the field measurements of V/C ratio. The calibrated parameters are shown in Table 6, along with the default values used in AIMSUN.

\section{Simulation and Analysis of the Alternative Scenarios}

Several scenarios to improve the roundabout performance can be experimented using the calibrated model. In this paper, two scenarios are discussed in the following.

\subsection{Alternative Scenario 1: Addition of Lane in Weaving Sections}

The roundabout can be improved by adding lanes in weaving sections. In this case, additional lanes are applied to the north and south weaving sections as shown in Figure 12.

The resulting changes in V/C ratios of each weaving section are shown in Table 7.

It is obvious that $\mathrm{V} / \mathrm{C}$ ratios have dropped significantly in the north and south weaving sections, an improvement in service level from $\mathrm{F}$ to $\mathrm{C}$.

Other performance measures have also improved more or less as is shown in Table 8.

\subsection{Alternative Scenario 2: Apply Signal Control}

In this scenario, besides adding lanes to the north and south weaving sections the 
Table 6. Comparison of the calibrated and the default parameters.

\begin{tabular}{ccccccc}
\hline & \multicolumn{3}{c}{ Default } & \multicolumn{3}{c}{ Calibrated } \\
\cline { 2 - 7 } Parameter & average & minimum & maximum & average & minimum & maximum \\
\hline Max Acceleration $\left(\mathrm{m} / \mathrm{s}^{2}\right)$ & 3 & 2.6 & 3.4 & 2.4 & 2.08 & 2.72 \\
Max Decceleration $\left(\mathrm{m} / \mathrm{s}^{2}\right)$ & 6 & 5 & 7 & 5.4 & 4.5 & 6.3 \\
Max Expected Speed $(\mathrm{km} / \mathrm{h})$ & 110 & 80 & 150 & 99 & 72 & 135 \\
Max Give-way Time $(\mathrm{s})$ & 10 & 5 & 15 & 8 & 4 & 12 \\
\hline
\end{tabular}

Table 7. Comparison of alternative scenario 1 and real-life scenario.

\begin{tabular}{ccccc}
\hline Weaving Section & East & North & East & South \\
\hline V/C Ratio of Realife Scenario & 0.71 & 0.82 & 0.77 & 0.85 \\
V/C Ratio of Alternative Scenario 1 & 0.67 & 0.73 & 0.75 & 0.74 \\
Variation Range & $-5.08 \%$ & $-10.61 \%$ & $-2.22 \%$ & $-12.75 \%$ \\
\hline
\end{tabular}

Table 8. Variation of other indexes in alternative scenario 1.

\begin{tabular}{cccc}
\hline Index & Queue Length & Travel Time & Delay \\
\hline Variation & $-1.39 \%$ & $-6.02 \%$ & $-23.17 \%$ \\
\hline
\end{tabular}

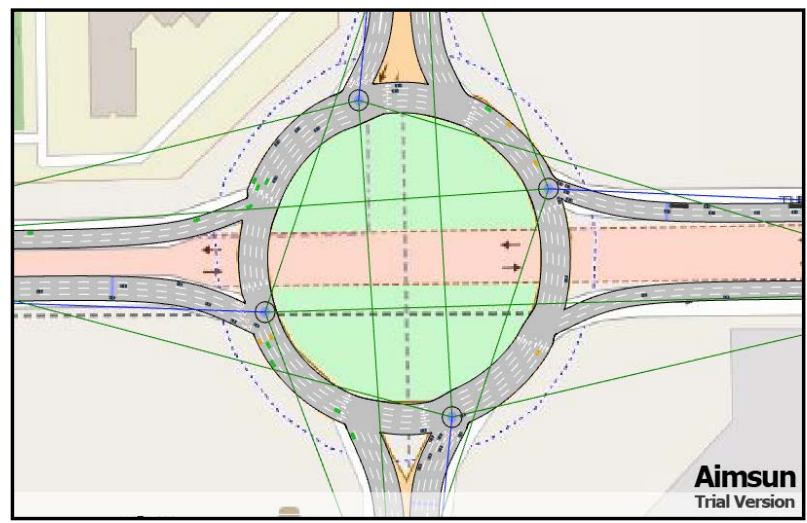

Figure 12. Addition of lane.

roundabout is subjected to fixed-time signal control as is demonstrated in Figure 13.

The resulting V/C ratios are shown in Table 9 and measures are shown in Table 10.

According to Table 9, the V/C ratio has dropped tremendously, while other indexes have deteriorated like Table 10 shows.

All in all, signal control, which is generally considered as an effective method, is actually not suitable for this intersection, whereas addition of lane is much more appropriate. 
Table 9. Comparison of alternative scenario 2 and real-life scenario.

\begin{tabular}{ccccc}
\hline Weaving Section & East & North & East & South \\
\hline V/C Ratio of Realife Scenario & 0.71 & 0.82 & 0.77 & 0.85 \\
V/C Ratio of Alternative Scenario 2 & 0.42 & 0.65 & 0.50 & 0.68 \\
Variation Range & $-40.68 \%$ & $-20.45 \%$ & $-36.40 \%$ & $-19.46 \%$ \\
\hline
\end{tabular}

Table 10. Variation range of other indexes in alternative scenario 2.

\begin{tabular}{cccc}
\hline Index & Queue Length & Travel Time & Delay \\
\hline Variation Range & $+55.96 \%$ & $+32.11 \%$ & $+89.50 \%$ \\
\hline
\end{tabular}

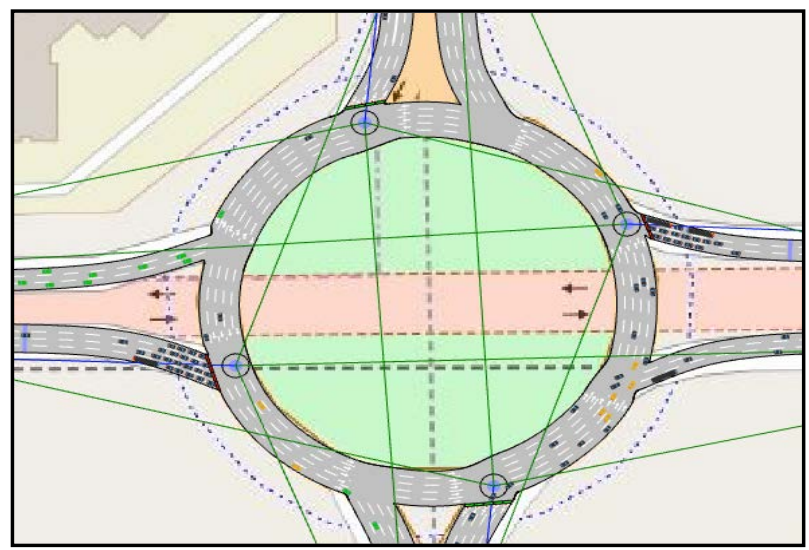

Figure 13. Apply signal control.

\section{Conclusion}

This article shows the process to evaluate and improve roundabouts. While the cases studied are in Changchun, the methodology adopted may be applicable to other cities in China. The use of microscopic simulations to model roundabouts is an efficient way to experiment with different improvement strategies.

\section{References}

[1] The Compilation Group of "Technical Guidelines for Traffic Impact Analysis of Construction Project” (2010) Technical Guidelines for Traffic Impact Analysis of Construction Project. 1st Edition. China Architecture \& Building Press. (In Chinese).

[2] An, Z.Z. (2008) Research on Capacity and Levels of Service for Roundabout. Master Thesis, Southeast University, China. (In Chinese).

[3] Li, Q.Y. and Sun, F. (2011) Evaluation Indexes Selection and Level-of-Service Classification for Roundabouts. Journal of Highway and Transportation Research and Development, 28, 131-135. (In Chinese).

[4] Chin, H.C. (1985) SIMRO: A Model to Simulate Traffic at Roundabouts. Traffic Engineering \& Control, 26, 109-113.

[5] Kotusevski, G. and Hawick, K.A. (2009) A Review of Traffic Simulation Software. MSc 
Thesis, Massey University.

[6] Septarina (2012) Micro-Simulation of the Roundabout at Idrottsparken Using AIMSUN. Master Thesis, Linköping University.

Submit or recommend next manuscript to SCIRP and we will provide best service for you:

Accepting pre-submission inquiries through Email, Facebook, LinkedIn, Twitter, etc. A wide selection of journals (inclusive of 9 subjects, more than 200 journals)

Providing 24-hour high-quality service

User-friendly online submission system

Fair and swift peer-review system

Efficient typesetting and proofreading procedure

Display of the result of downloads and visits, as well as the number of cited articles Maximum dissemination of your research work

Submit your manuscript at: http://papersubmission.scirp.org/ 